\title{
Effect of foundation embedment on the response of a multi-story building to earthquake excitation
}

\author{
Mohammed Hamood ${ }^{1, *}$, and Sajjad Abid ${ }^{1}$ \\ ${ }^{1}$ Building and Construction Engineering Department, University of Technology, Baghdad, Iraq
}

\begin{abstract}
During an earthquake, the behaviour of any structure is affected not only by the superstructure response, but also by the response of the soil beneath. Recent structural failure patterns have indicated the significance of soil-structure interaction ( $\mathrm{SSI}$ ) effects. The present study focuses on SSI analysis considering the embedment depth of the foundation of a symmetric six stories reinforced concrete $(\mathrm{RC})$ space bare frame building resting on stiff soil and subjected to seismic loading. The finite element analysis software ANSYS v17.2 is used. Time history (TH) analysis has been adopted. The Response in terms of lateral displacements, base shear forces, base moments and variation in natural time periods are calculated from the analysis of the soil foundation structure interaction (SFSI) model. Results are compared with that obtained from conventional method assuming rigid support at the base (fixed base) of the structure. The results show that the SFSI considering different embedment depths are significant in altering the seismic response of the multi-story building (MSB).
\end{abstract}

\section{Introduction}

Over the last decades, the dynamic Soil Foundation Structure -Interaction (SFSI) has attracted an intensive interest among researchers and engineers in the fields of soil dynamics, structural dynamics and wave mechanics over the world. The investigation methods include experimental and analytical studies, since, the experimental investigations are very expensive and time consuming [1], calibration of present computer models with a similar previous experimental research can be a certainty, with the methods of analysis and the availability of computer programs, it is in principle possible to evaluate the dynamic response of any structure foundation system to any excitation of the base. Such evaluations, however, can be no better than the assumptions underlying the analyses. Many researchers like Milind [2], Faramarz et al [3] and Ola [4] recommended the inclusion of SSI effects on multi-story buildings. In this work the general Finite Element Analysis (FEA) program ANSYS has been used to evaluate the structural response.

\section{Soil foundation structure Interaction}

SFSI is defined as when an earthquake excitation occurs, the structure and the ground vibrate with influencing each other .This phenomenon is called "Dynamic Soil Structure Interaction (DSSI)" and is recognized as being very important for the seismic design of structures [5] . Soil structure interaction (SSI) has an impact on the structure response mainly in four basic aspects. These effects can be epitomized as first increased lateral displacements of the structure, second lengthened natural time period of the system, also, higher damping in the system and finally changing the base shear force depending on the dynamic characteristics of the soil also the structural system and frequency content of the excitation motion [6], degree of influence of SSI on response of building depends on foundation system type, stiffness of ground and dynamic characteristics of building itself, that is, damping factor and natural period [5].

\section{Modelling of soil}

In this research, Mohr-Coulomb criterion is used to model the soil; Mohr-Coulomb model is applicable to three-dimensional stress space models while being a simple model (Refer Figure (1)) with only two strength parameters to describe the plastic behavior. By means of true triaxial tests, researchers have indicated that stress combinations causing failures in real soil sample quite well agreed with the hexagonal shape of the failure pattern [7].

Mohr-Coulomb criterion is a first-order model shown in Fig.s (1 and 2), it is an elastic-perfectly plastic model which is often used to model the behavior of soil. In general stress state, the model's stress-strain behaves linearly in the elastic range, with two defining parameters from Hooke's law (Young's modulus, E and Poisson's ratio, v). Failure criterion is defined by two parameters (the angle of friction $\phi$, and cohesion, c) and also a parameter to describe the flow rule (dilatancy angle, $\psi$ which comes from the use of non-associated flow rule

\footnotetext{
Corresponding author:mjh_smm@yahoo.com
} 
which is used to simulate the realistic irreversible change in volume caused by shearing).

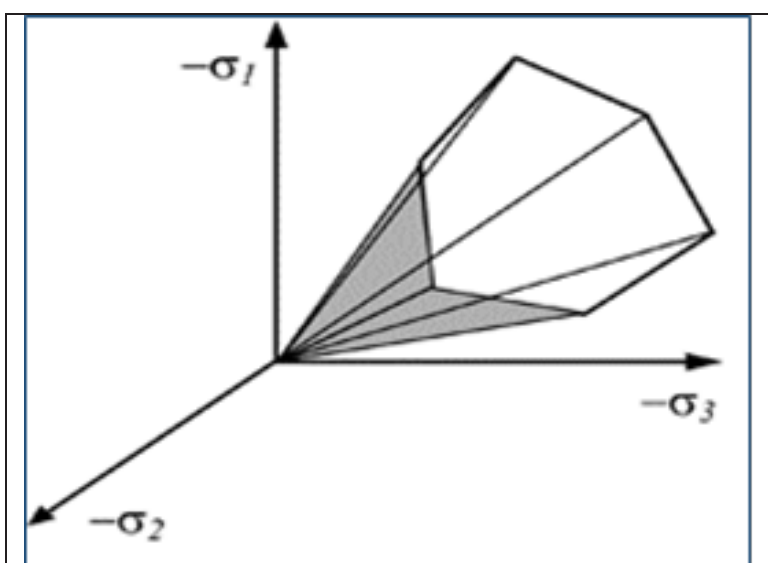

Fig. 1. Mohr-Coulomb yield surface in principal stresses [9].

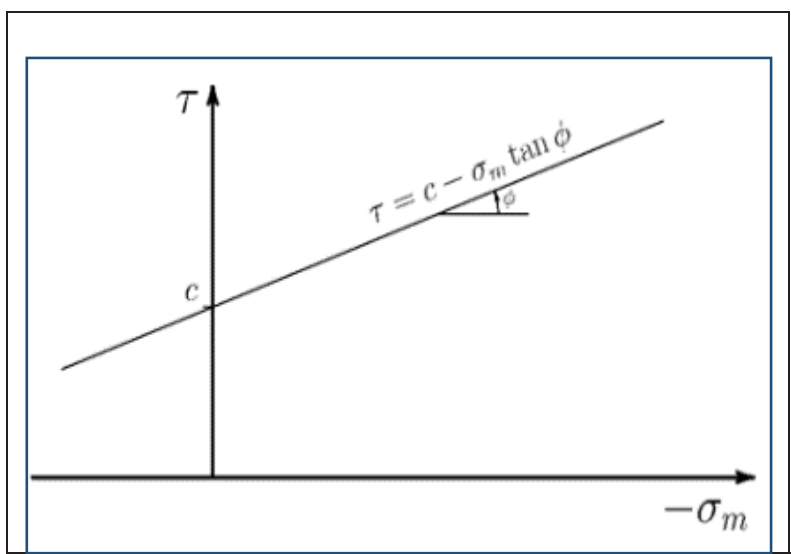

Fig. 2. Mohr-Coulomb yield surface as mean stress versus shear [10].

\section{General description of the structure}

The studied building is designed using structural design and analysis software ETABS 2016, according to building code requirements for structural concrete (ACI $318 \mathrm{M}-14)$, seismic design category $\mathrm{D}$ is used, the building consists of two bays in both directions with a spacing of $6 \mathrm{~m}$ in each bay, the building comprising of a six stories with a height of $3 \mathrm{~m}$ as shown in Fig.s 3and 4, the girders dimensions are $\mathrm{b}=0.4 \mathrm{~m}, \mathrm{~h}=0.5 \mathrm{~m}$ while the columns have a square section of $0.5 \mathrm{~m}$, the longitudinal rebar have $16 \mathrm{~mm}$ diameter with four bars at the corners for both beams and columns, stirrups with a $12 \mathrm{~mm}$ diameter used in both the columns and beams with a spacing for both columns and beams is $150 \mathrm{~mm}$.

\section{Loading on the structural models}

The building models in the present study were loaded vertically (superimposed dead load, live loads and selfweight of the members) and laterally (seismic loads). It was assumed a live load of $(2 \mathrm{kN} / \mathrm{m} 2)$, superimposed dead load $(1.5 \mathrm{kN} / \mathrm{m} 2)$ in addition to self-weight and seismic load, these loads are used to analyze all FEM models.
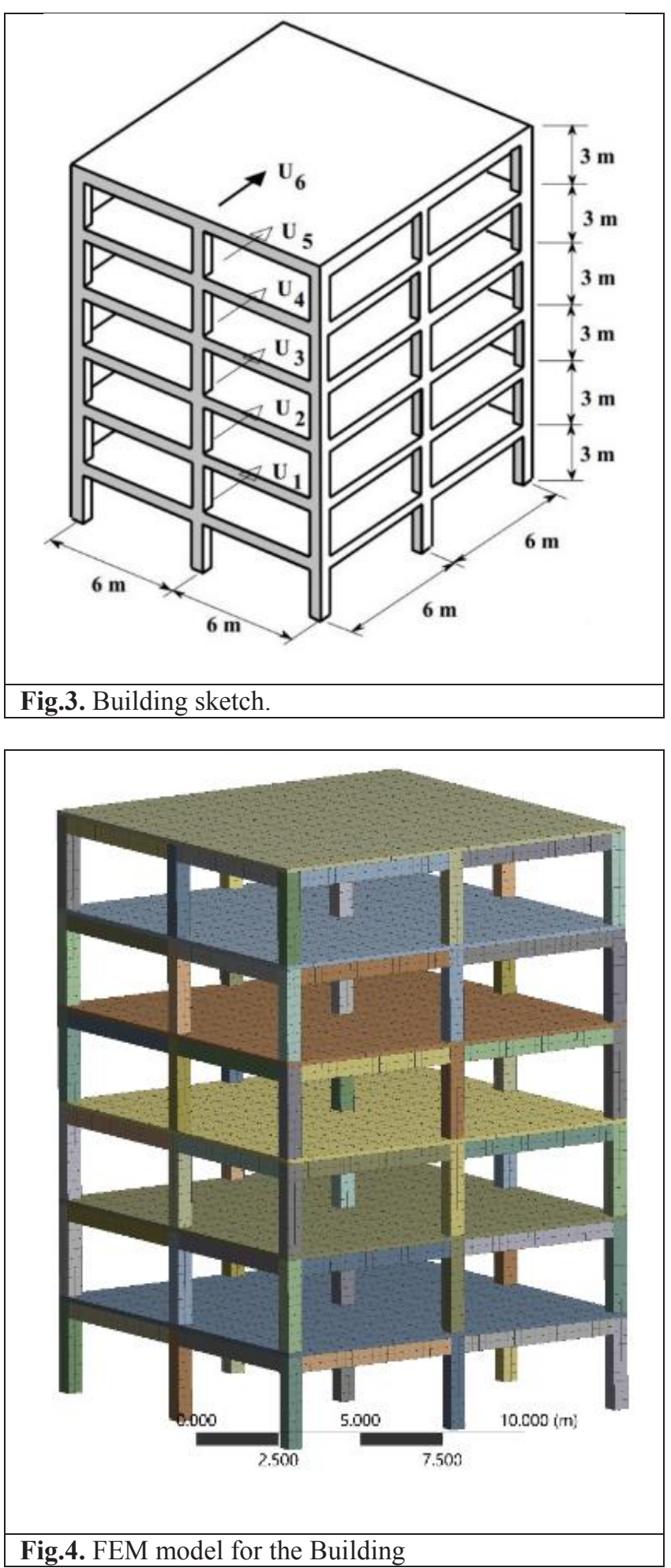

\section{Types of modelling elements with their constitutive models}

A finite element modeling is done for the superstructure along with the supporting soil using available finite 
element software ANSYS. The elements described below have been used in modeling of the structure and the soil:

\subsection{SOLID65}

Is an element used for modeling of 3-D solids without or with reinforcing bars (rebar). The element has an ability to crushing in compression and cracking in tension. The concrete material has the properties of crushing, plastic deformation, cracking (in three orthogonal directions), and creep [8]. Drucker-Prager yield criterion has been used as a constitutive model for concrete.

\subsection{BEAM189}

This element is 3-D quadratic solid with three-nodes, it has six degrees of freedom at each node; these include rotations about the $\mathrm{x}, \mathrm{y}$, and $\mathrm{z}$ directions and translations in the $\mathrm{x}, \mathrm{y}$, and $\mathrm{z}$ directions, creep, elasticity, plasticity and other nonlinear material models are supported. A cross-section referencing more than one material associated with this element type can be a built-up. BEAM189 is based on beam theory of Timoshenko, which is a first-order shear-deformation theory: assuming transverse-shear strain is constant through the crosssection (that is, cross-sections remain undistorted and plane after deformation) [8] bilinear isotropic hardening model has been used.

\subsection{SOLID45}

This is an element used for modeling of 3-D solid materials. The element is defined by eight nodes with three degrees of freedom at each node: translations in the nodal $\mathrm{x}, \mathrm{y}$, and $\mathrm{z}$ directions. The element has creep, plasticity, stress stiffening, swelling, large strain, and large deflection capability [8], Mohr-coulomb model is used for soil formulation.

\section{Properties of materials:}

Properties of Materials are summarized in the table 1.

\section{Input seismic excitation:}

As it is impossible to predict ground motion characteristics that may happen in the future at a construction site as the property of the ground motion is described by many factors such as seismic wave propagation from the source to site, fault mechanism and the amplification characteristics of ground. The significant factors of ground motions affecting the structure's response results are frequency contents, peak foundation acceleration, shapes of waveform and duration of ground motion in this study The 1940 El Centro earthquake has been selected see figures (5) and (6) for more details.
Table 1. Properties of materials used.

\begin{tabular}{|c|c|c|c|}
\hline Material & $\begin{array}{l}\text { Element } \\
\text { type }\end{array}$ & \multicolumn{2}{|l|}{ Properties } \\
\hline \multirow{7}{*}{ Concrete } & \multirow{7}{*}{ SOLID65 } & Density $\left(\mathrm{kg} / \mathrm{m}^{\mathrm{a}}\right)$ & 2408.2 \\
\hline & & Poisson Ratio & 0.2 \\
\hline & & $\begin{array}{l}\text { Modulus of Elasticity } \\
(\mathrm{MPa})\end{array}$ & 29386 \\
\hline & & Drucker-Prager & \\
\hline & & $\begin{array}{l}\text { Uniaxial compressive } \\
\text { strength }(\mathrm{MPa})\end{array}$ & 38.1 \\
\hline & & $\begin{array}{l}\text { Uniaxial tensile } \\
\text { strength }(\mathrm{MPa})\end{array}$ & 3.5 \\
\hline & & $\begin{array}{l}\text { Biaxial compressive } \\
\text { strength }(\mathrm{MPa})\end{array}$ & 44.2 \\
\hline \multirow{6}{*}{ Rebar } & \multirow{6}{*}{ BEAM189 } & Density $\left(\mathrm{kg} / \mathrm{m}^{\mathrm{a}}\right)$ & 7849 \\
\hline & & Poisson Ratio & 0.3 \\
\hline & & $\begin{array}{l}\text { Modulus of Elasticity } \\
\text { (MPa). }\end{array}$ & 199100 \\
\hline & & Bilinear Isotropic $\mathrm{Ha}$ & ening \\
\hline & & Yield Stress (MPa) & 578 \\
\hline & & $\begin{array}{l}\text { Tangent Modulus } \\
(\mathrm{mPa})\end{array}$ & 1991 \\
\hline \multirow{9}{*}{ Soil } & \multirow{9}{*}{ SOLID45 } & Density $\left(\mathrm{kg} / \mathrm{m}^{2}\right)$ & 1939 \\
\hline & & Poisson Ratio & 0.28 \\
\hline & & Shear Modulus (MPa) & 623.41 \\
\hline & & \multicolumn{2}{|c|}{ Mohr-Coulomb } \\
\hline & & $\begin{array}{l}\text { Initial Inner Friction } \\
\text { Angle (degree) }\end{array}$ & 40 \\
\hline & & Initial Cohesion (Pa) & 5000 \\
\hline & & Dilatancy Angle & 10 \\
\hline & & $\begin{array}{c}\text { Residual Friction Angle } \\
\text { (degree) }\end{array}$ & 38 \\
\hline & & Residual Cohesion (Pa) & 0 \\
\hline
\end{tabular}

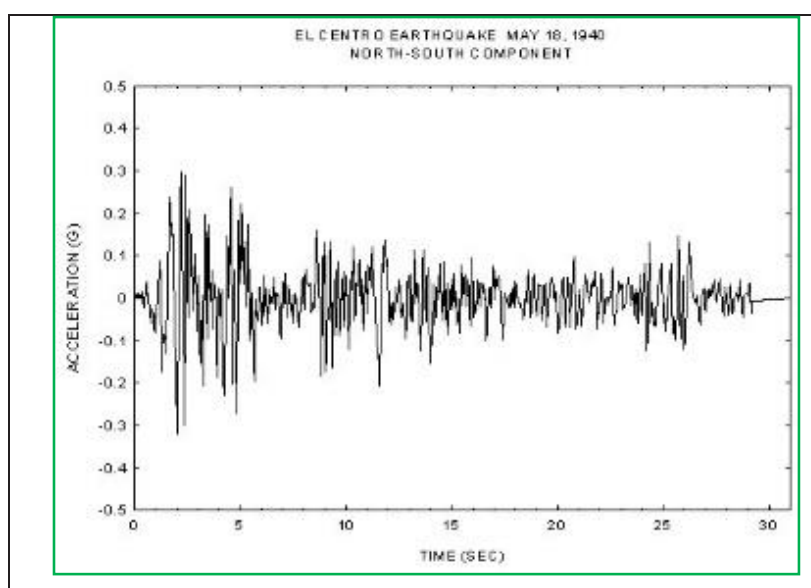

Fig.5. Earthquake acceleration time history [10]. 


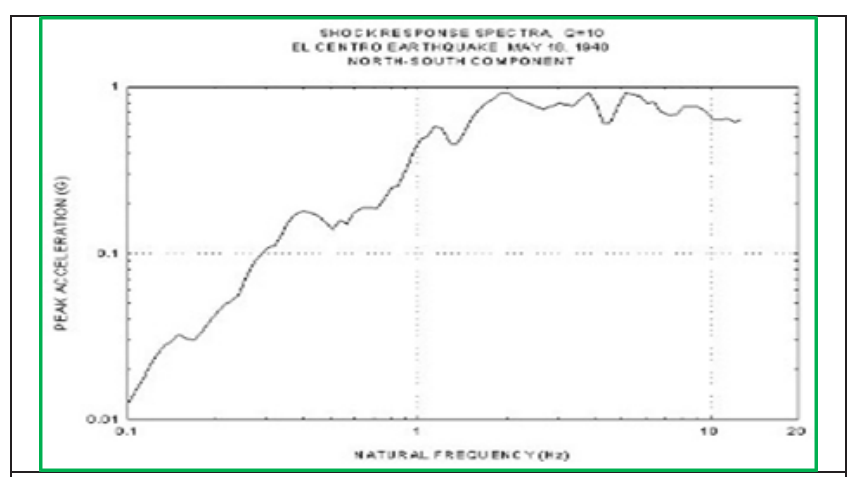

Fig. 6. Earthquake response spectrum [10].

\section{Objectives}

1- The present work focuses on the analysis of SFSI of six stories reinforced concrete bare frame for the following cases of analysis:

- Without considering the beneath soil i.e. without SSI effect (fixed case)

- With subsoil condition i.e. soil structure interaction analysis for different embedment condition with raft foundation.

2- Dynamic linear time history analysis method is carried out for all the models.

\section{Results and discussion}

\subsection{Displacement response of the building:}

SFSI, especially for multi-story buildings resting on relatively soft soils may significantly amplify the interstory drifts and lateral displacements. This amplification of lateral deformations may result in changing the performance level of the structure. Thus, an extensive dynamic analysis to estimate the realistic performance level of a structure should consider the effects of SFSI on the model, the effect of SSI on the story lateral displacement of six stories building has been studied using three different embedment depths of the building, the lateral displacements with time history are presented in Fig.(7). It is observed that the displacement increase occurs in SSI models, the displacement increases more from embedment depth of one story to embedment depth of three stories even though the embedment depth have increased as could be seen clearly from the Table (2).Many researchers indicated this like Janardhan [11], Nithya [12], also he indicated that the low to mid rise buildings is mostly affected by SSI effects, the increased lateral displacement is due to soil flexibility.

\subsection{Base shear}

One of the primary inputs considered for seismic designs is seismic base shear. Base shear is defined as; the maximum expected lateral force that is estimated to occur at the base of a structure as result of seismic ground excitation. The effect of SSI on base shear of building frames with different embedment depths are presented in Table (3) and Figure (8). It is observed that base shear of the building is increased by $52 \%$ to $256 \%$ due to SSI effect.

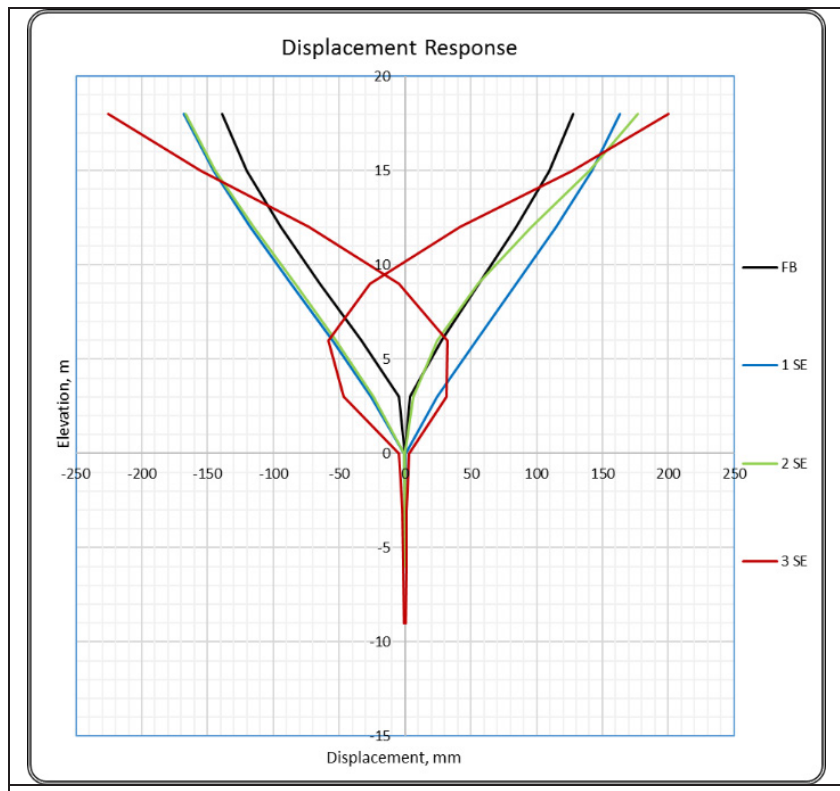

Fig. 7. Lateral displacement versus elevation.

Table 2. Maximum and minimum top displacement response summary.

\begin{tabular}{|l|c|c|c|c|}
\hline $\begin{array}{c}\text { Displace- } \\
\text { ment } \\
\text { response }\end{array}$ & $\begin{array}{c}\text { Max. } \\
\text { Displace } \\
\text {-ment } \\
\text { (mm) }\end{array}$ & $\begin{array}{c}\text { Min. } \\
\text { displac } \\
\text {-ement } \\
\text { (mm) }\end{array}$ & $\begin{array}{c}\text { \% of } \\
\text { Max. } \\
\text { FB } \\
\text { respon } \\
\text { se }\end{array}$ & $\begin{array}{c}\text { \% of } \\
\text { Min. } \\
\text { FB } \\
\text { respons } \\
\text { e }\end{array}$ \\
\hline $\begin{array}{l}\text { FB (fixed } \\
\text { base) }\end{array}$ & 128 & 140 & 100 & 100 \\
\hline $\begin{array}{l}\text { Embedm- } \\
\text { ent depth } \\
\text { of 1 story }\end{array}$ & 164 & 171 & 128 & 122 \\
\hline $\begin{array}{l}\text { Embedm- } \\
\text { ent depth } \\
\text { of 2 story }\end{array}$ & 177 & 168 & 138 & 120 \\
\hline $\begin{array}{l}\text { Embedm- } \\
\text { ent depth } \\
\text { of 3 story }\end{array}$ & 204 & 228 & 159 & 162 \\
\hline
\end{tabular}

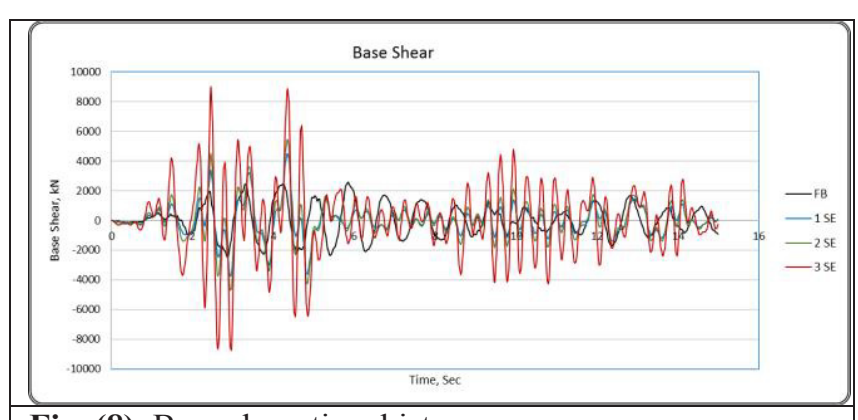

Fig. (8). Base shear time history. 
Table (3). Maximum and minimum base shear summary

\begin{tabular}{|c|c|c|c|c|}
\hline $\begin{array}{c}\text { Base } \\
\text { Shear } \\
(\mathrm{kN})\end{array}$ & $\begin{array}{c}\text { Max. } \\
\text { Shear }\end{array}$ & $\begin{array}{c}\text { Min. } \\
\text { Shear }\end{array}$ & $\begin{array}{c}\text { \% of } \\
\text { Max. FB } \\
\text { Shear }\end{array}$ & $\begin{array}{c}\text { \% of Min. } \\
\text { FB Shear }\end{array}$ \\
\hline FB & 2560 & 2460 & 100 & 100 \\
\hline 1 SE & 4478 & 3751 & 174 & 152 \\
\hline 2 SE & 5450 & 4712 & 212 & 191 \\
\hline S SE & 34581 & 34034 & 95 & 104 \\
\hline
\end{tabular}

\subsection{Base moment}

The base moment of a multi-story building was computed for different embedment depths based on time history analysis. The base moment obtained from the multi-story building with flexible base is compared with that obtained from the multi-story building with FB. The variations of base moment evaluated from different embedment depths are shown in Table (4) and Fig.(9). It is found that the moment of base of the multi-story building increases with increased embedment depth of foundation. It is also seen that the base moment is maximum in multi-story building with FB as compared to SSI case. the base moment of multi-story building obtained from the $1 \mathrm{SE}$ building is less than that obtained from the 1 and 3 SE building, the overall base moment is less than that with FB as can be seen in the Table 4.

Table 4. Maximum and minimum base moment summary.

\begin{tabular}{|c|c|c|c|c|}
\hline $\begin{array}{c}\text { Base } \\
\text { Moment } \\
\text { (kN.m) }\end{array}$ & $\begin{array}{c}\text { Max. } \\
\text { Mome } \\
\text { nt }\end{array}$ & $\begin{array}{c}\text { Min. } \\
\text { Mom } \\
\text { ent }\end{array}$ & $\begin{array}{c}\text { \% of } \\
\text { Max. FB } \\
\text { Moment }\end{array}$ & $\begin{array}{c}\text { \% of } \\
\text { Min. FB } \\
\text { Moment }\end{array}$ \\
\hline FB & 36046 & 32487 & 100 & 100 \\
\hline 1 SE & 29578 & 29783 & 82 & 91 \\
\hline 2 SE & 27357 & 30616 & 75 & 94 \\
\hline 3 SE & 34581 & 34034 & 95 & 104 \\
\hline
\end{tabular}

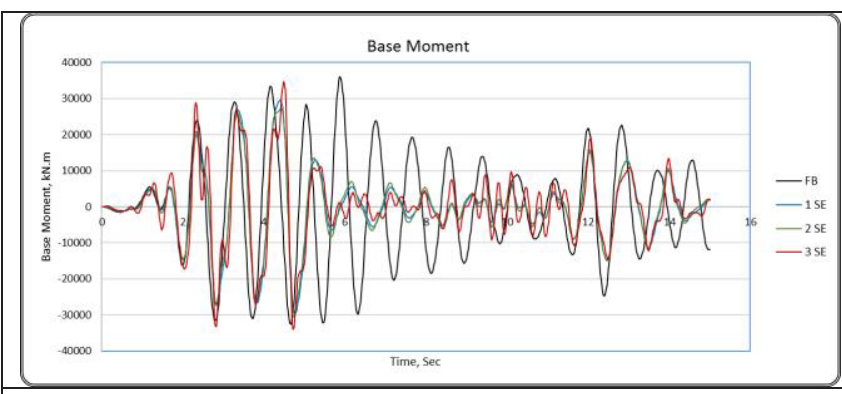

Fig. 9. Base moment time history.

\subsection{Multi-story displacement response}

Multi-Story displacement response of each floor level is an important factor that has been evaluated. The Story displacement response is investigated for studied multistory building using different embedment depths for the foundation. It can be seen from Fig. (7), that the lateral displacement of the building is increasing even though the embedment depth of the foundation has been increased to reach a maximum increase in response of $102 \%$ compared to FB case, while the cases of 1 and 2 stories embedded have not shown that much difference in response compared to each other.

\subsection{Max inter-story drifts}

Story drift ratio is the maximum relative displacement of each floor divided by the height of the same floor is an important parameter that has been evaluated. The story drift ratio response is investigated for studied multi-story building using different embedment depths for the foundation. It can be concluded as shown in the figure(10) that the maximum inter-story case is at the base of the building when the SSI is considered regardless of the embedment depth, while in the case of fixed base (FB) the second story is the governing interstory drift.

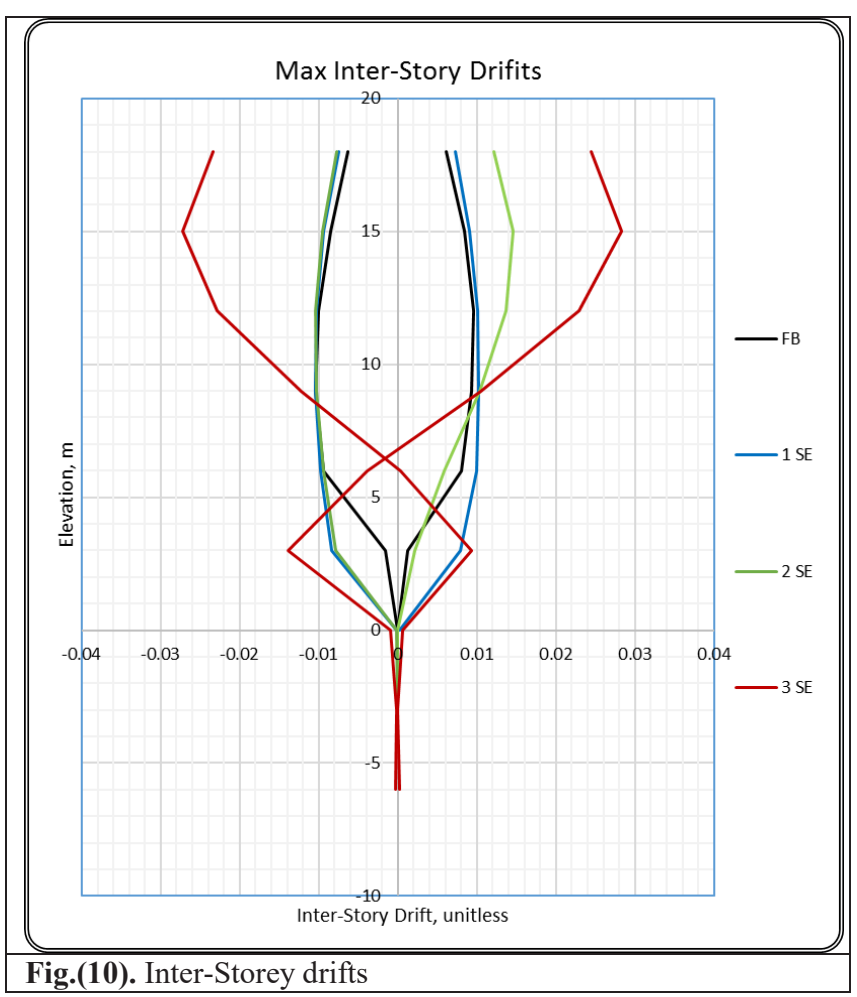

\subsection{Fundamental period}

The period of vibration is one of the fundamental parameters in the force-based design of structures as this parameter determines the spectral acceleration and turn the base shear force to which the building should be designed [14]. The fundamental period of vibration, $\mathrm{T}$, is a function of the stiffness of the lateral load resisting system and the building mass [15]. The fundamental periods of the building are summarized in the table below. 
Table (5). Fundamental period.

\begin{tabular}{|c|c|c|c|}
\hline $\begin{array}{c}\text { Fundamental } \\
\text { Period for Case: }\end{array}$ & Frequency $(\mathrm{Hz})$ & $\begin{array}{c}\text { Period } \\
(\mathrm{sec})\end{array}$ & \% of FB \\
\hline FB & 1.1815 & 0.8464 & 100 \\
\hline $1 \mathrm{SE}$ & 1.0164 & 0.9839 & 116 \\
\hline $2 \mathrm{SE}$ & 1.064 & 0.9398 & 111 \\
\hline $3 \mathrm{SE}$ & 1.0233 & 0.9772 & 115 \\
\hline
\end{tabular}

\section{Conclusions}

This study aimed to investigate the effects of SoilStructure Interaction (SSI) with the foundation embedment depth of the building. Based on the results from this study, the following conclusions can be drawn:

- Due to soil flexibility, lateral displacement is increased as compared to fixed base, the lateral displacement is increased up to twice of fixed base lateral displacement response, the increase embedment showed no beneficial effect on displacement response of the multi-story building.

- While many codes around the world suggest methods to reduce the base shear when considering SSI, this study confirmed recent studies that are not the case always and the accurate response of structures is influenced by the media on which the structures is founded.

- The SSI tends to reduce the overall base bending of the multi-story building to some extent.

- The maximum story drift in the case of fixed base occurs at first story while on the case of SSI with varying embedment depths is at the base, i.e. it behaves closer to pinned base.

- The natural period of the structure is usually longer when it is analyzed with flexible base systems.

\section{References}

1. B. Furkan and F. Birdal, Nat. Hazards Earth Syst. Sci., (2012).

2. V. M. Milind, International Journal of Scientific \& Engineering Research, vol. 6, no. 10, (August-2015).

3. F. Khoshnoudian, E. Ahmadi, F.A. Nik, pp. 453-464, (2013).

4. O. A. Hussien, University of Technology, Bagdad/Iraq, (2015).

5. K. Miura, Graduate School of Engineering Hiroshima University, (2009).

6. P. W. John and J. D. Andrew, Foundation Vibration Analysis, Elsevier, (2004).
7. G. M, "True triaxial tests on dense sands," Balkema, Rotterdam, (1984).

8. ANSYS, Inc., ANSYS Mechanical APDL Theory Reference, Pennsylvania, United States: ANSYS, Inc., (1970).

9. D. F. Craig, A. S. Ahmed and D. L. Michael, The American Society of Mechanical Engineers, (May 20, 2013).

10. T. Irvine, "El Centro Earthquake," May 1940. [Online] Available, http://www.vibrationdata.com/elcentro.htm. [Accessed 152 2017].

11. J. Shanmugam, International Journal of Computer Applications, (2015).

12. N. Chandran, A. Rajan, International Journal of Emerging Technology and Advanced Engineering, vol. 4, no. Issue 11, 11, (November 2014).

13. R. Ditommaso, M. Vona, M. R. Gallipoli, M. Mucciarelli, Nat. Hazards Earth Syst. Sci., (4 July 2012).

14. A. R. Shehata , International Journal of Advanced Structural Engineering, (03 September 2013).

15. J. Raju, SSRG International Journal of Civil Engineering, pp. 135-141, (April 2015). 